\title{
Drug-drug interactions in common mental disorders patients attended in primary health care
}

1,2 Borges, T. L.; ${ }^{2}$ Vedana, K. G. G.; ${ }^{2}$ Castilho, E. C. D.; ${ }^{1,2}$ Moscovici, L.; ${ }^{2 M i a s s o, ~ A . ~ I . ~}$ ${ }^{1}$ Centro Universitário Estácio de Ribeirão Preto; ${ }^{2}$ Escola de Enfermagem de Ribeirão Preto, Universidade de São Paulo.

\section{OBJECTIVES}

The objectives of this research were:

- to compare potential drug-drug interactions (DDIs) frequency and characterization among Common Mental Disorders (CMD) patients;

- to verify associations between CMD with potential DDIs, demographic, use of psychoactive drugs, number of medication prescribed and severity of potential DDIs.

\section{BACKGROUND}

High-risk interactions occur mostly with narrow therapeutic index drugs, which includes many psychotropic medications. Primary Health Care (PHC) plays an important role in Brazilian health assistance to CMD patients. However, there are few studies regarding DDI in CMD patients in PHC settings.

\section{MATERIALS AND METHODS}

- This is a quantitative, cross-sectional and descriptive correlational study carried in PHC services in Brazil.

- It was interviewed a stratified sample of 430 patients.

- Statistics was performed using univariate and multivariate analysis having CMD as dependent variable.

\section{REFERENCES}

Borges TL, Miasso Al, Vedana KGG, Telles-Filho PCP, Hegadoren KM (2015) Prevalence in the use of psychotropics and associated factors in primary health care. Acta Paulista Enferm 28:344-9.

Fortes S, Lopes CS, Villano LAB, Campos MR, Gonçalves DA, Mari JJ (2011) Common mental disorders in Petrópolis-RJ: A challenge to integrate mental health into primary care strategies. Rev Bras Psiquiatr 33(2):150-6.

Marengoni A, Onder G (2015) Guidelines, polypharmacy, and drug-drug interactions in patients with multimorbidity. BMJ 350:h1059.

\section{RESULTS}

- 190 patients had more than two medications prescribed, being eligible to the analysis.

- Among them 58.4\% had DDI and 53.1\% had CMD.

- $28 \%$ of the patients presented severe potential DDI in their prescription.

- Moderate DDI was observed in $62.9 \%$ of the prescriptions

- Associations with CMD were found between age, monthly income, psychotropic medication and severity of DDI.

Table 1. Distribution of patients treated at PHC according to presenting potential DDI classified for severity according to Self-Report Questionnaire-20 result $(n=190)$

\begin{tabular}{|c|c|c|c|c|}
\hline \multirow{2}{*}{ DDI Severity } & \multicolumn{3}{|c|}{ Self-Report Questionnaire-20 result } & \multirow{2}{*}{$P$ value } \\
\hline & No & Yes & Total & \\
\hline Severe & $15(26,3 \%)$ & $25(46,3 \%)$ & $40(36.03 \%)$ & \\
\hline Moderate & $42(73,7 \%)$ & $25(46,3 \%)$ & $67(60.36 \%)$ & $<0,01$ \\
\hline Light & $0(0 \%)$ & $4(7,4 \%)$ & $4(3.6 \%)$ & \\
\hline Total & $57(100 \%)$ & $54(100 \%)$ & $111(100 \%)$ & \\
\hline
\end{tabular}

Table 2. Distribution of potentially severe drug interactions with greater absolute frequency equal or more than two, detected in patients $(n=190)$ treated in primary health care according to Common Mental Disorders.

\begin{tabular}{llll}
\hline \multirow{2}{*}{ Drug-drug interaction } & \multicolumn{3}{l}{ Self Report Questionnaire result } \\
\cline { 2 - 4 } & $\mathbf{N o}$ & $\mathbf{Y}$ & Total \\
& $\mathbf{N}(\boldsymbol{\%})$ & $\mathbf{N}(\boldsymbol{\%})$ & $\mathbf{N}(\boldsymbol{\%})$ \\
\hline Anlodipine + simvastatin & $5(41.66 \%)$ & $2(10 \%)$ & $7(21.9 \%)$ \\
Amitriptiline + levothyroxine & $2(16.66 \%)$ & $4(20 \%)$ & $6(18.8 \%)$ \\
Amitriptiline + fluoxetine & - & $4(20 \%)$ & $4(12.5 \%)$ \\
Fluoxetine + propranolol & - & $4(20 \%)$ & $4(12.5 \%)$ \\
Amitriptiline + clonidine & $1(8.33 \%)$ & $2(10 \%)$ & $3(9.4 \%)$ \\
Fluoxetine + haloperidol & - & $2(10 \%)$ & $2(6.3 \%)$ \\
Amiodarone + simvastatin & $2(16.66 \%)$ & - & $2(6.3 \%)$ \\
Carbamazepine +simvastatin & $1(8.33 \%)$ & $1(5 \%)$ & $2(6.3 \%)$ \\
Amitriptiline + sertraline & $1(8.33 \%)$ & $1(5 \%)$ & $2(6.3 \%)$ \\
\hline Total & $\mathbf{1 2 ( 1 0 0 \% )}$ & $\mathbf{2 0 ( 1 0 0 \% )}$ & $\mathbf{3 2 ( 1 0 0 \% )}$ \\
\hline
\end{tabular}

\section{CONCLUSIONS}

The results found highlight the risk for DDI in CMD patients emphasizing the urgent need of the investigation and implementation of strategies aiming this public. 